\title{
Effect of estrus synchronization on daily somatic cell count variation in goats according to lactation number and udder health status
}

\author{
A. Mehdid, ${ }^{\star}$ J. R. Díaz,† A. Martí,† G. Vidal, ${ }^{\star}$ and C. Peris ${ }^{\star 1}$ \\ *Institut de Ciència i Tecnologia Animal, Universitat Politècnica de València, Cami de Vera, s/n, Valencia, Spain \\ †Departamento de Tecnología Agroalimentaria, Escuela Politécnica Superior de Orihuela, Universidad Miguel Hernandez, Ctra. Beniel, Km, 3,2, \\ 03312 Orihuela, Spain
}

\section{ABSTRACT}

Two repeated experiments were carried out in 2 different years to study the effect of estrus on somatic cell count (SCC) in dairy goats. In the first year, 36 Murciano-Granadina goats were used [12 primiparous and 24 multiparous; 22 healthy and 14 with an intramammary infection (IMI)] and, after a 6 -d pre-experimental period, were divided into 2 groups according to lactation number, udder health status, SCC, and milk production. One group was kept as a control, whereas the other received an estrus synchronization hormonal treatment lasting $11 \mathrm{~d}$. At 24, 48, and $72 \mathrm{~h}$ after cessation of the hormone treatment, goats were placed in contact with a buck to confirm that they were in estrus. For 32 consecutive days (6 pre-experimental, 11 in hormone treatment, and 15 post-treatment) the SCC per gland and udder were monitored in all animals. In the second year, we repeated the same experimental design using a total of 38 Murciano-Granadina breed goats (12 primiparous and 26 multiparous; 26 healthy and 12 with IMI). Throughout this experiment, milk yield and composition were also recorded daily for each goat. Upon termination of the hormonal treatment, the SCC in udder milk increased significantly in the treatment group compared with the control group over 3 consecutive days. This increase was observed for year (1 and 2), parity (primiparous and multiparous), and udder health status (healthy and IMI). The $\log _{10}$ SCC (cells $/ \mathrm{mL}$ ) increased from $5.5 \pm 0.09$ before estrus to $6.04 \pm 0.09$ during treatment; therefore, the geometric mean of the SCC increased 3.5 times during treatment. The maximum values obtained in healthy glands of primiparous goats (geometric mean $=0.37$ million cells $/$ $\mathrm{mL}$ ) were lower than in healthy glands (1.1 million cells $/ \mathrm{mL})$ or infected glands (1.7 million cells $/ \mathrm{mL})$ of multiparous goats. The increase in SCC observed during estrus (200\% increase in geometric means) could not be explained by the changes in milk production,

Received November 19, 2012.

Accepted March 18, 2013.

${ }^{1}$ Corresponding author: cperis@dca.upv.es which only fell by $13 \%$. During estrus, the percentage of protein and dry matter in the milk also increased significantly. We concluded that it is necessary to consider the presence of estrus to correctly interpret milk SCC, as an indirect method for detecting IMI or as a commercial milk quality parameter.

Key words: somatic cell count, goat, estrus

\section{INTRODUCTION}

Milk SCC is commonly used in dairy cattle, sheep, and goats as an indirect detection method for IMI and, in bulk tank milk, as a commercial milk quality parameter (Bergonier et al., 2003; Paape et al., 2007; Pirisi et al., 2007). However, many works have reported that noninfectious factors affecting SCC are more important in goats than in other species (Paape et al., 2001; Gonzalo, 2005). Although plenty of information is available on the effect of main noninfectious factors, such as stage and number of lactation (Dulin et al., 1983; Kalogridou-Vassiliadou, 1992; De Crémoux et al., 1996; Luengo et al., 2004), other factors influencing SCC variability are not sufficiently described. For example, Wilson et al. (1995) found that $77 \%$ of individual milk SCC variability could not be explained on the basis of known infectious or noninfections factors.

Some works have indicated that estrus in dairy goats can induce a transient increase in SCC. This was observed under on-field conditions during the mating season (Lerondelle et al., 1992; Wilson et al., 1995; Calderini et al., 1996) and under experimental conditions in which estrus occurred naturally (Moroni et al., 2007) or was hormonally induced (Aleandri et al., 1996; McDougall and Voermans, 2002; Christodoulopoulos et al., 2008). Some authors (Paape et al., 2001) suggest that the increase in SCC associated with the presence of estrus could also be due to a decrease in milk production; however, McDougall and Voermans (2002) found that estrus increases SCC without a significant decrease in milk production.

Moreover, other aspects in the relationship between estrus and SCC in goat milk are not yet sufficiently clear. For example, no works studying whether the es- 
trus effect is different in primiparous goats compared with multiparous are available. Likewise, some controversy exists as to whether estrus may affect SCC differently depending on the health status of the gland. Thus, Bergonier et al. (2003) stated that estrus may cause a greater SCC increase in glands with IMI than in healthy ones, whereas McDougall and Voermans (2002) found no effects of estrus on milk SCC when healthy and IMI udders were compared; however, we must point out that the latter study was conducted with a low number of infected udders $(\mathrm{n}=4$ per treatment).

The aim of this paper is to examine whether estrus' effect on SCC is different in primiparous goats compared with multiparous goats or in healthy udders compared with IMI udders. Moreover, we intend to confirm that the increase in SCC during estrus cannot be explained by changes in the animals' milk production.

\section{MATERIALS AND METHODS}

\section{Experimental Design}

The present study was carried out at an experimental farm of the Polytechnic University of Valencia, using Murciano-Granadina dairy goats. Annual health checks done by official veterinary services showed that the farm was free from brucellosis, tuberculosis, Mycoplasma agalactiae, and caprine arthritis-encephalitis virus.

The experiment was repeated in two years, both in June and July, using a total of 74 goats in their third to fifth month of lactation. In the first year, 36 goats were used (12 in first lactation: 8 healthy and 4 with unilateral IMI; 24 in second lactation or higher: 14 healthy and 10 with unilateral IMI), which, after a 6-d pre-experimental period, were distributed into 2 balanced groups according to lactation number, udder health status, SCC, and milk production. One group received an estrus synchronization hormonal treatment, whereas the other received no treatment (control). The hormone treatment applied consisted of $11 \mathrm{~d}$ with polyurethane foam vaginal sponges impregnated with 30 mg of fluorogestone acetate (Sincropart, Ceva Salud Animal, Barcelona, Spain) and i.m. administration of $300 \mathrm{IU}$ of equine chorionic gonadotropin (Sincropart PMSG, Ceva Salud Animal) and $0.5 \mathrm{~mL}$ of Enzaprost (synthetic analog of $\mathrm{PGF}_{2 \alpha}$, Ceva Salud Animal) $48 \mathrm{~h}$ before sponge removal. For 32 consecutive days (6 preexperimental, 11 in hormone treatment, and 15 after sponge removal), the SCC per each gland and the whole udder were monitored in all animals. In addition, 6 health checks were also performed on each gland on experimental $\mathrm{d}-17,-13,-7,0,7$, and 14 , with $\mathrm{d} 0$ being the final day of hormonal treatment (sponges removed at $1200 \mathrm{~h}$ ). All infections were due to CNS, except one case caused by Corynebacterium spp. Estrus detection was carried out in all goats (estrus and control groups) $24 \mathrm{~h}$ after removing the sponges, and detection was repeated again at 33 and $48 \mathrm{~h}$ in the treatment group goats that showed no estrus symptoms. For estrus detection, goats were individually transferred to a pen with a buck, a doe being considered in estrus when she accepted mounting. In the first year, one primiparous and another multiparous goat from the control group, both initially healthy, suffered subclinical and clinical mastitis, respectively, during the hormone treatment, and were not included in the results.

In the second year, the previous design was repeated, using a total of 38 goats (12 in first lactation: 10 healthy and 2 with unilateral IMI; 26 in second lactation or higher: 16 healthy, 8 with unilateral IMI and 2 with bilateral IMI; all infections caused by CNS), of which 19 were allocated to the treatment group and the other 19 to control group, using the same criteria described for the yr 1 experiment. In addition, the production and composition (fat, protein, lactose, and DM) of the milk were also recorded daily for each animal. In the second year, the results for 3 goats from the treatment group were not taken into account: 2 because no estrus was detected (1 primiparous and the other multiparous, both infected) and 1 healthy multiparous goat that suffered an accident before sponge removal causing a sudden drop in milk production.

\section{Management and Feeding of the Goats}

Goats were machine milked once daily $(0800 \mathrm{~h})$ in a routine including machine stripping and dipping of the teats in iodine after teatcup removal. The milking parlor $(2 \times 12)$ had 6 clusters (Almatic cluster G50, Delaval Agri, Tumba, Sweden) and a milk pipeline at $1.0 \mathrm{~m}$ above the platform (midlevel). Milking parameters were set at a rate of 90 pulsations per minute, a vacuum level of $40 \mathrm{kPa}$, and a $60 \%$ pulsation ratio. In each experiment, all goats were permanently stabled and kept together in the same straw-bedded pen (available surface $=1.5 \mathrm{~m}^{2} /$ goat; feeder $=0.4 \mathrm{~m} /$ goat ) and received the same feed offered per head (as-fed; commercial concentrate for lactating goats $=1.2 \mathrm{~kg} / \mathrm{d}$; alfalfa hay $=1.0 \mathrm{~kg} / \mathrm{d}$; citrus pulp $=2.0 \mathrm{~kg} / \mathrm{d}$; ad libitum barley straw). Water was freely available in the pens.

\section{Measured Variables}

Total daily milk (machine milk plus machinestripped milk) from each animal was recorded using 3.5-L jars, graduated in 50-mL divisions (Esneder Ref. 90001, Industrias Berango S.L., Urduliz; Spain). 
Samples for SCC and milk composition analyses were taken in $50-\mathrm{mL}$ polypropylene flasks with a hermetic seal. To determine the SCC per gland, $40 \mathrm{~mL}$ of milk were collected from each teat separately, by manual milking before teatcup attachement. Composition and SCC of udder milk were analyzed in a sample of the total milk extracted from each animal. All samples were kept refrigerated $\left(4^{\circ} \mathrm{C}\right)$ between 24 and $36 \mathrm{~h}$ until analysis in the laboratory. The SCC was analyzed using the Fluoro-opto-electronic method (ISO, 2006) with a Fossomatic 5000 (Foss, Hillerød, Denmark). Milk composition (fat, CP, lactose, and DM) was determined by midrange infrared spectroscopy using a MilkoScan FT120 (Foss).

To obtain samples for bacteriological analysis, teats were carefully cleaned with $70 \%$ ethanol and the first 3 streams of foremilk were discarded. Approximately 5 $\mathrm{mL}$ of milk were collected aseptically from each gland. Samples were kept at $4^{\circ} \mathrm{C}$ for a maximum of $12 \mathrm{~h}$ until bacteriological analysis. Twenty microliters of each sample were sowed on blood agar plates (5\% washed sheep erythrocytes; Biomerieux, Lyon, France). Plates were incubated aerobically at $37^{\circ} \mathrm{C}$ and examined at 24 h, $48 \mathrm{~h}$, and $7 \mathrm{~d}$. Cultures with 5 or more identical colonies were considered positive for IMI. Bacterial groups were identified according to National Mastitis Council recommendations (Harmon et al., 1990).

\section{Statistical Analysis}

Results for SCC of udder milk samples, recorded daily in both experiments in a total of 69 goats ( 34 in the first year and 35 in the second), were statistically analyzed with a repeated measures model including the fixed effects of year (1 and 2), group (treatment and control), parity (primiparous and multiparous), health status (healthy and infected), and day (11 d during hormonal treatment and $15 \mathrm{~d}$ thereafter); the interactions terms of group $\times$ day, year $\times$ group $\times$ day, parity $\times$ group $\times$ day, health status $\times$ group $\times$ day; and the random effect of goat $(\mathrm{n}=69)$ within year, group, parity, and health status.

The SCC was analyzed in $\log _{10}$ to normalize the distribution (Ali and Shook, 1980). The milk production and composition variables were analyzed using the previous model, but without considering the year effect or its interactions (the variables cited were only recorded in the second year) and adding a covariable to the model corresponding to the mean of the values obtained in the 6 pre-experimental days (before the onset of hormone treatment). All these statistical analyses were performed with the SAS Statistical Package MIXED procedure (SAS Institute, 2008).

\section{RESULTS AND DISCUSSION}

Estrus detection was carried out on the first and second day after sponge removal (d 1 and 2; d 0 being when sponges were removed) to confirm that most of the goats from the treatment group (35 of 37) were in heat at this point. The 2 goats from this group that showed no symptoms of estrus on these days were not considered in the results. In contrast, no goats from the control group manifested estrus behavior on $\mathrm{d} 1$.

Somatic cell count in the udder milk samples was significantly affected by lactation number $\left(\log _{10} \mathrm{SCC}=\right.$ $5.50 \pm 0.08$ and $5.86 \pm 0.06$ for primiparous and multiparous goats, respectively; $P<0.001)$, udder health status $(5.52 \pm 0.06$ and $5.84 \pm 0.08$ for healthy and IMI udders, respectively; $P<0.01)$, day $(P<0.001)$, group $\times$ day interaction $(P<0.001)$, and, finally, year $\times$ group $\times$ day triple interaction $(P<0.001)$.

The fact that the group $\times$ day interaction was significant indicates that the evolution of SCC throughout the experiment in the treatment and control groups was different. If we consider the results for both years jointly, we find that the SCC increased significantly in the treatment group compared with the control group on d $0(P<0.05)$, d $1(P<0.001)$, and $\mathrm{d} 2(P<$ 0.01 ; Table 1$)$. In contrast, on all other days of the experiment cell counts for the treatment group showed no significant differences compared with the control group. The year $\times$ group $\times$ day interaction was also significant $(P<0.001)$, which may be because the treatment group cell counts began to rise earlier in the experiment carried out in yr 1 (significant differences on $\mathrm{d} 0,1$, and 2; Table 1 ) than in the experiment in year 2 (significant differences on d 1, 2 and 3; Table 1). The increment in SCC during estrus was important, as the maximum value reached $\left(\log _{10} \mathrm{SCC}=6.04 \pm\right.$ 0.09 ; joint analysis in yr 1 and 2) corresponded to a geometric mean of 1.10 million cells $/ \mathrm{mL}$, representing a 3.5-fold increase compared with cell counts before estrus $\left(\log _{10} \mathrm{SCC}=5.5 \pm 0.09\right.$; geometric mean $=$ 0.31 million cells $/ \mathrm{mL}$ ). This outcome is similar to that found by Moroni et al. (2007) in spontaneous estrus of multiparous IMI-free goats, who also reported that the SCC increased 4-fold compared with values observed in the luteal phase. However, Christodoulopoulos et al. (2008) found that estrus increased the SCC only 1.3fold (from 0.8 to 1.05 million cells $/ \mathrm{mL}$ ). As reported by Moroni et al. (2007), the SCC increase begins with luteal regression (decreased progesterone) and an increase in blood estrogens. In our case, despite applying a strict estrus synchronization protocol, we must point out that considerable individual variability in the relationship between estrus and SCC was observed. For 
Table 1. Daily evolution of SCC (in $\log _{10}$, cells $/ \mathrm{mL}$ ) of udder milk samples in goats receiving an estrus synchronization treatment and in untreated goats (control) in 2 experiments performed in year 1 and year 2

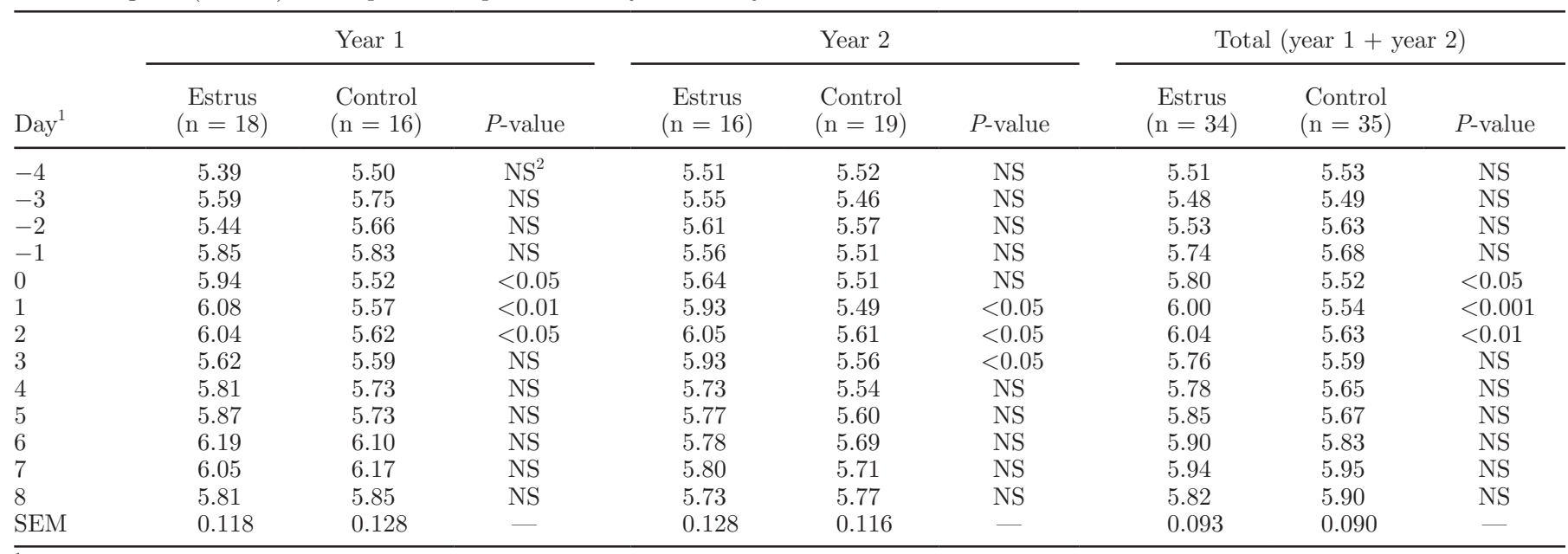

${ }^{1}$ The hormonal treatment for estrus synchronization was administered from $\mathrm{d}-11$ to 0 .

${ }^{2} \mathrm{NS}=$ not significant $(P>0.05)$.

example, in some goats SCC were multiplied 60 -fold during estrus, whereas in other goats cell counts barely increased at all. Moreover, in some of these animals cell counts began to increase on $\mathrm{d}-1$ and 0 (both samples collected before sponge removal), and in other animals the counts began to rise on $\mathrm{d} 1$ and even on $\mathrm{d} 2$ ( $2 \mathrm{~d}$ after sponge removal).

The lactation number $\times$ group $\times$ day interaction was not significant. Figure 1 shows how, in primiparous goats as well as multiparous goats, the treatment group SCC increased after the hormonal treatment compared with the control group (significant differences on d 1 and 2). That result demonstrates for the first time that estrus also increases SCC in primiparous goats. The health status $\times$ group $\times$ day interaction was not significant either, therefore the hormonal estrus-induction treatment, both in healthy and infected udders, led to a significant $(P<0.05)$ increase in SCC $(\mathrm{d} 1$ and 2$)$ compared with control group (Figure 2). This finding is also notable, as practically no information is available on how estrus affects udders with IMI, in which the SCC in milk is usually higher than in healthy udders (Raynal-Ljutovac et al., 2007).

Figure 3 shows the SCC geometric mean evolution per gland. We observed that the maximum SCC values reached during estrus were greater in infected glands (1.7 million cells $/ \mathrm{mL}$ ) than in healthy multiparous glands (1.1 million cells $/ \mathrm{mL})$, which in turn presented higher values than healthy primiparous glands $(0.37$ million cells $/ \mathrm{mL}$ ). However, if we consider the maximum increment in SCC with respect to the pre-estrus values (infected glands $=\sim 0.45$ million cells $/ \mathrm{mL}$; healthy multiparous glands $=\sim 0.30$ million cells $/ \mathrm{mL}$; healthy multiparous glands $=\sim 0.10$ millions cells $/ \mathrm{mL}$ ), the values obtained are quite similar in the 3 udder types (3.8, 3.7, and 3.7, respectively). Thus, this finding does not allow us to accept the hypothesis posited by
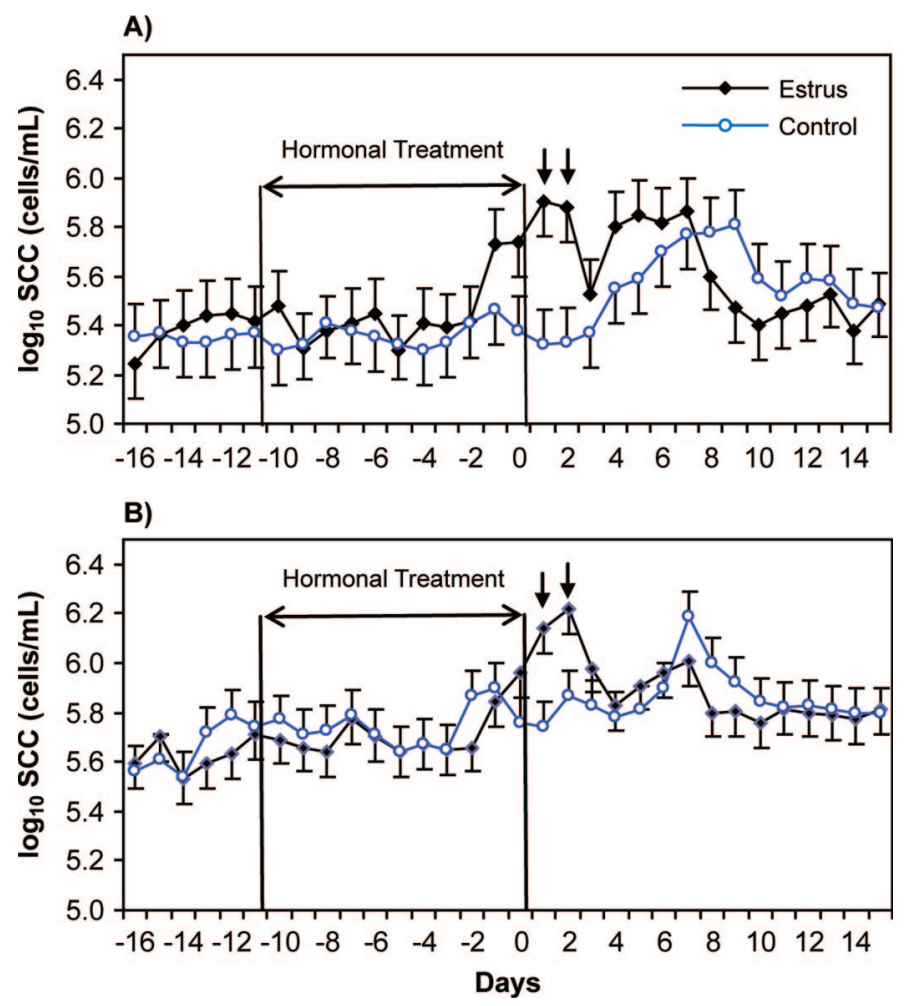

Figure 1. Daily evolution of $\log _{10}$ SCC (mean \pm SEM) in udder milk in a group of goats receiving estrus synchronization hormonal treatment (Estrus) and another group of untreated goats (Control), separately by lactation number (A: primiparous, B: multiparous). Arrows indicate days with significant differences $(P<0.05)$ between the 2 groups. Color version available in the online PDF. 


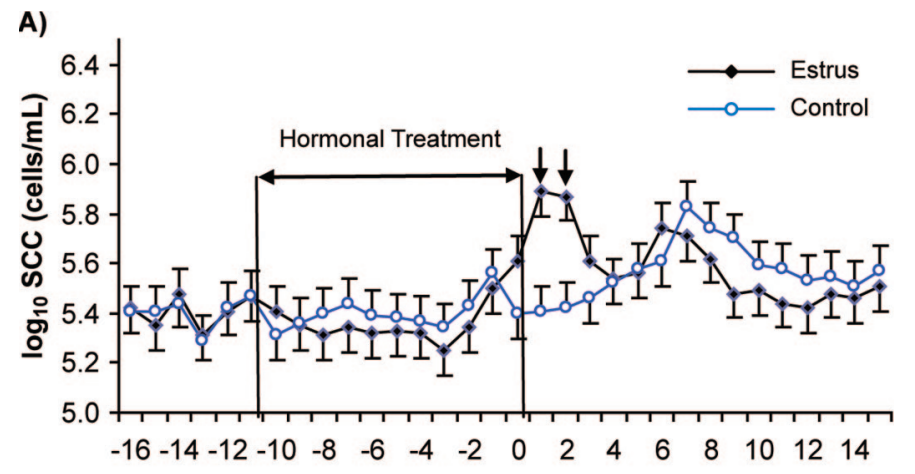

B)

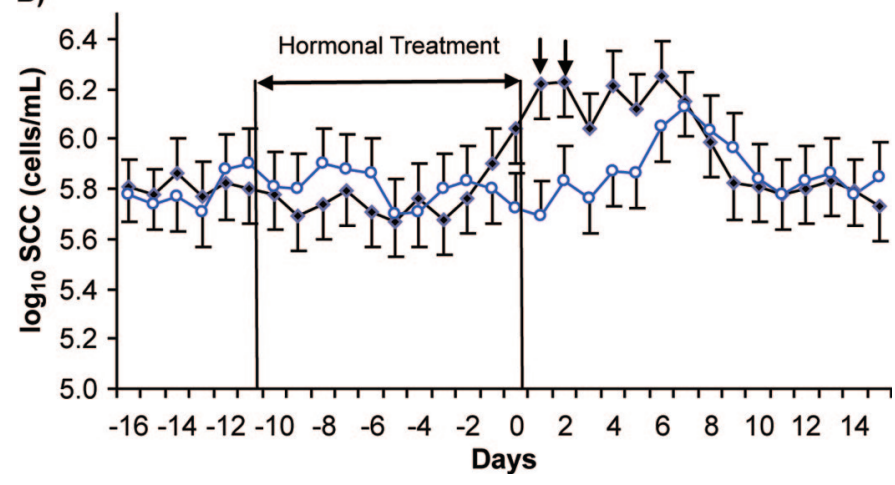

Figure 2. Daily evolution of $\log _{10}$ SCC (mean \pm SEM) in udder milk in a group of goats receiving estrus synchronization hormonal treatment (Estrus) and another group of untreated goats (Control), separately by udder health state (A: healthy udders, b: infected udders). Arrows indicate days with significant differences $(P<0.05)$ between the 2 groups. Color version available in the online PDF.

Bergonier et al. (2003), that estrus may cause a greater SCC increase in glands with IMI than in healthy ones.

Another notable aspect of the results obtained (Table 1, Figures 1 and 2) is that the control group SCC increased on $\mathrm{d} 6$ and 7 , although the differences from the treatment group were not significant. This SCC increase in the control group was also observed by McDougall and Voermans (2002), and would supposedly indicate that the goats that came into estrus after hormonal treatment would have induced a group estrus in the control group goats, which were in seasonal anoestrus (Walden-Brown et al., 1999). Thus, in a farm carrying out hormonally induced estrus in a group of goats from a flock, it is likely that the bulk tank milk cell counts would remain higher for at least 1 wk after the initial onset of estrus.

Milk production was significantly affected by parity $(2,098 \pm 41$ and $2,344 \pm 24 \mathrm{~mL} / \mathrm{d}$, for primiparous and multiparous goats, respectively; $P<0.001$ ), day $(P<0.001)$, and group $\times$ day interaction $(P<0.01)$. The latter may be explained because the production dropped significantly in the treatment group on d 0,1 , and 2 compared with the control group, whereas for the rest of the experimental period the differences were not significant (Table 2 ). On the $3 \mathrm{~d}$ cited, the milk production average in the treatment group was $13 \%$ lower than in the control group $(1,959 \pm 51.5$ vs. $2,260 \pm$ $42.0 \mathrm{~mL} / \mathrm{d}$, respectively; $P<0.001)$. This drop in milk production during estrus was also observed by Peaker and Linzell (1974) in goats. McDougall and Voermans (2002) also reported that estrus tended to reduce milk production, although the differences did not become significant. In any case, the drop in milk production observed in the present study is still not enough to explain, alone, through a dilution or concentration effect, the increase in SCC; which is in disagreement with that suggested by Paape et al. (2001). Indeed, in our work the geometric means of the SCC increased from 0.35 to 1.1 million cells $/ \mathrm{mL}\left(\log _{10} \mathrm{SCC}=5.55\right.$ and 6.05 , respectively; yr 2, Table 1), that is, an increase of more than $200 \%$, whereas milk production only decreased by $13 \%$. Therefore, this suggests that estrus per se is responsible for the increase in SCC, probably due to physiological mechanisms still unknown (McDougall and Voermans, 2002)

Finally, milk composition was significantly affected by the lactation number (fat $=P<0.05$; protein $=P<$ $0.01 ; \mathrm{DM}=P<0.05$; lactose $=P>0.05$ ), udder health status (lactose $=P<0.05$; other components $=P>$ 0.05), day (all components $=P<0.001$ ), and group $\times$ day interaction (protein $=P<0.001 ; \mathrm{DM}=P<0.01$; other components $=P>0.05$ ). The fact that the group $x$ day interaction was significant for protein is because the treatment group milk presented significantly higher values on $\mathrm{d} 1,2,3$, and 4 compared with the control group, whereas for the rest of the experimental period the differences were not significant (Table 2). The same occurred with DM, although in this case the differences were significant only on d 1 and 2 (Table 2 ). In contrast, the fat and lactose contents did not differ $(P>0.05)$

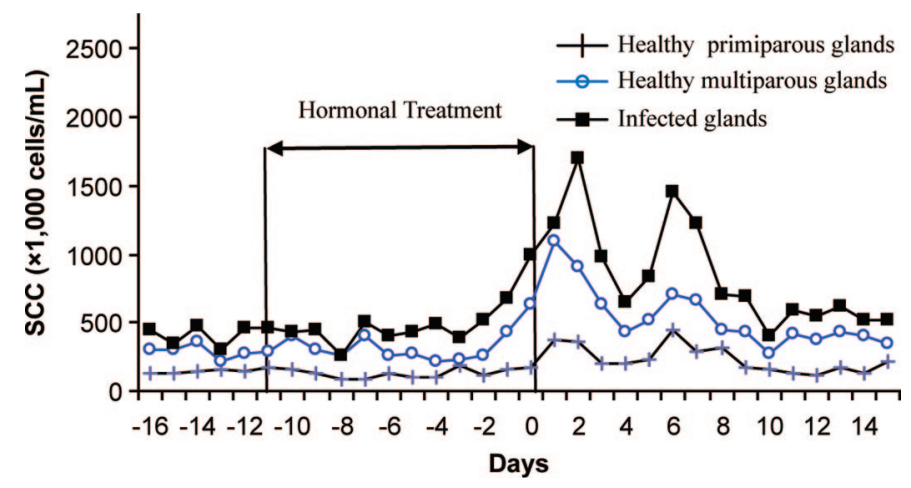

Figure 3. Daily evolution of geometric means of SCC in 3 type of mammary glands (healthy primiparous, healthy multiparous, and infected), all belonging to goats that received an estrus synchronization hormonal treatment. Color version available in the online PDF. 
Table 2. Daily evolution of milk yield and composition in goats receiving an estrus synchronization treatment $(\mathrm{n}=16)$ and in untreated goats (control; $\mathrm{n}=19)$

\begin{tabular}{|c|c|c|c|c|c|c|c|c|c|c|}
\hline Day $^{1}$ & \multicolumn{2}{|c|}{ Milk yield $(\mathrm{mL} / \mathrm{d})$} & \multicolumn{2}{|c|}{ Fat (g/100 g) } & \multicolumn{2}{|c|}{ Protein (g/100 g) } & \multicolumn{2}{|c|}{ Lactose (g/100 g) } & \multicolumn{2}{|c|}{ DM (g/100 g) } \\
\hline-2 & 2,194 & 2,214 & 4.61 & 4.82 & 3.36 & 3.38 & 4.41 & 4.43 & 13.34 & 13.55 \\
\hline-1 & 2,236 & 2,191 & 4.57 & 4.60 & 3.30 & 3.32 & 4.36 & 4.36 & 13.19 & 13.19 \\
\hline 0 & 2,169 & 2,319 & 4.73 & 4.80 & 3.38 & 3.30 & 4.38 & 4.42 & 13.47 & 13.44 \\
\hline 3 & $2,103^{\mathrm{b}}$ & $2,327^{\mathrm{a}}$ & 4.67 & 4.68 & $3.46^{\mathrm{a}}$ & $3.29^{\mathrm{b}}$ & 4.40 & 4.34 & 13.51 & 13.22 \\
\hline 4 & 2,240 & 2,395 & 4.43 & 4.46 & $3.52^{\mathrm{a}}$ & $3.40^{\mathrm{b}}$ & 4.38 & 4.34 & 13.27 & 13.10 \\
\hline 5 & 2,102 & 2,275 & 4.68 & 4.56 & 3.54 & 3.45 & 4.30 & 4.32 & 13.50 & 13.25 \\
\hline 6 & 2,250 & 2,280 & 4.59 & 4.40 & 3.35 & 3.42 & 4.28 & 4.29 & 13.40 & 13.10 \\
\hline 7 & 2,340 & 2,288 & 4.44 & 4.35 & 3.43 & 3.34 & 4.26 & 4.27 & 13.10 & 12.86 \\
\hline 8 & 2,295 & 2,200 & 4.38 & 4.48 & 3.40 & 3.38 & 4.29 & 4.28 & 12.95 & 12.93 \\
\hline SEM & 75.4 & 61.4 & 0.165 & 0.133 & 0.041 & 0.033 & 0.035 & 0.030 & 0.205 & 0.166 \\
\hline
\end{tabular}

${ }^{\mathrm{a}, \mathrm{b}}$ For each variable, means within a row with different superscripts differ $(P<0.05)$.

${ }^{1}$ The hormonal treatment for estrus synchronization was administered from $\mathrm{d}-11$ to 0 .

between the 2 experimental groups throughout the study. These results agreed with those of Christodoulopoulos et al. (2008), as these authors also found that milk protein increased significantly during goat estrus, whereas fat and lactose did not vary significantly. From the data available, it is not clear why protein content increases during estrus. One initial hypothesis could be the existence of a concentration effect as a result of the drop in milk production. However, this should also have caused a significant increase in fat content, which was not the case. A second hypothesis would be that the somatic cells might interfere in the protein analysis by midinfrared spectroscopy. However, in a recent laboratory experiment in which we added somatic cells to goat milk samples, no correlation was observed between the SCC and the milk protein content (unpublished data); therefore, this hypothesis should also be ruled out. A third hypothesis could be that similar changes occur during estrus as those taking place in mastitis (an increase in SCC and blood proteins in milk; RaynalLjutovac et al., 2007). Nevertheless, this explanation is also open to question, as when IMI is present the lactose content is also reduced, something which does not occur during estrus.

In any case, the results of this study, along with those found in the literature, suggest that during estrus an association exists between the increase in SCC and increased protein content. For example, both the SCC and protein content of milk are slightly increased in buffaloes in estrus (Akhtar et al., 2008), whereas in cows (Cowan and Larson, 1979; Anderson et al., 1983; Horrell et al., 1985) and camels (Atigui et al., 2013) it was observed that estrus had no effect on SCC or milk protein content. This aspect should be the subject of future study.

\section{CONCLUSIONS}

In dairy goats, the presence of hormonally induced estrus causes an important and transitory increase of SCC in milk. In a group of animals in estrus, the average of cell counts increase approximately 3.5 -fold compared with the counts before estrus, and occurs both in healthy goats and infected animals and primiparous and multiparous goats. The increase in SCC that takes place during estrus is physiological in nature, as it cannot be explained by the changes in milk production. It is therefore necessary to consider the presence of estrus to correctly interpret the milk SCC as an indirect method of detecting IMI or as a commercial milk quality parameter.

\section{REFERENCES}

Akhtar, M. S., A. A. Farooq, M. Hussain, and M. Aziz. 2008. Effect of estrus on somatic cell count, protein and fat contents in milk of nili-ravi buffaloes. Pak. J. Agric. Sci. 45:339-341.

Aleandri, M., A. Fagiolo, P. Calderini, R. Colafrancesco, G. Giangolini, R. Rosati, and F. De Michelis. 1996. Studies conduced on somatic cells counts of goats milk. Pages 65-70 in Proc. Intern. Symp. Somat. Cells Milk Small Rumin. R. Rubino, ed. EAAP Publication No. 77, Bella, Italy. Wageningen Pers, Wageningen, the Netherlands.

Ali, A. K. A., and G. E. Shook. 1980. An optimum transformation for somatic cell concentration in milk. J. Dairy Sci. 63:487-490.

Anderson, K. L., A. R. Smith, S. L. Spahr, B. K. Gustafsson, J. E. Hixon, P. G. Weston, E. H. Jaster, R. D. Shanks, and H. L. Whitmore. 1983. Influence of the estrous cycle on selected biochemical and cytologic characteristics of milk of cows with subclinical mastitis. Am. J. Vet. Res. 44:677-680. 
Atigui, M., M. Hammadi, and T. Khorchani. 2013. Effects of oestrus on milk yield and composition in Tunisian Maghrebi camels (Camelus dromedarius). Emir. J. Food Agric. 25:291-295.

Bergonier, D., R. De Crémoux, R. Rupp, G. Lagriffoul, and X. Berthelot. 2003. Mastitis of dairy small ruminants. Vet. Res. 34:689-716.

Calderini, P., R. Colafrancesco, A. Fagiolo, M. E. Reitano, and F. De Michelis. 1996. Somatic cells count in milk from mastitis-free goats intensively reared and controlled until the sixth lactation. Pages 177-181 in Proc. Intern. Symp. Somat. Cells Milk Small Rumin. R. Rubino, ed. EAAP Publication No. 77, Bella, Italy, September 25-27, 1994. Wageningen Pers, Wageningen, the Netherlands.

Christodoulopoulos, G., N. Solomakos, P. D. Katsoulos, A. Minas, and S. K. Kritas. 2008. Influence of oestrus on the heat stability and other characteristics of milk from dairy goats. J. Dairy Res. $75: 64-68$.

Cowan, C. M., and L. L. Larson. 1979. Relationship of the estrous cycle to milk composition. J. Dairy Sci. 62:546-550.

De Crémoux, R., R. Pillet, M. Ducelliez, V. Heuchel, and B. Poutrel. 1996. Influence du nombre et du stade de lactation sur les numerations cellulaire du lait chevre. Pages 161-165 in Proc. Int. Symp. Somat. Cells Milk Small Rumin. R. Rubino, ed. EAAP Publication No. 77, Bella, Italy. Wageningen Pers, Wageningen, the Netherlands.

Dulin, A. M., M. J. Paape, W. D. Schultze, and B. T. Weinland. 1983. Effect of parity, stage of lactation, and intramammary infection on concentration of somatic cells and cytoplasmic particles in goat milk. J. Dairy Sci. 66:2426-2433.

Gonzalo, C. 2005. Somatic cell of sheep and goat milks: Analytical, sanitary, productive and technological aspects. Bull. Int. Dairy Fed. 0501/Part 3:128-133. IDF, Geneva, Switzerland.

Harmon, R. J., R. J. Eberhart, D. E. Jasper, B. E. Langlois, and R. A. Wilson. 1990. Microbiological Procedures for the Diagnosis of Bovine Udder Infection. National Mastitis Council, Arlington, VA.

Horrell, R. I., K. L. Macmillan, R. Kilgour, and K. Bremner. 1985. Changes in milk yield and composition at oestrus in dairy cows. J. Dairy Res. 52:9-16.

ISO. 2006. ISO 13366-2/IDF 148-2: Milk-Enumeration of Somatic Cells-Part 2: Guidance on the Operation of Fluoro-opto-electronic Counter. International Organization for Standardization, Geneva, Switzerland.
Kalogridou-Vassiliadou, D. 1992. Somatic cell counts in relation to infection status of the goat udder. J. Dairy Res. 59:21-28.

Lerondelle, C., Y. Richard, and J. Issartial. 1992. Factors affecting somatic cell counts in goat milk. Small Rumin. Res. 8:129-139.

Luengo, C., A. Sanchez, J. C. Corrales, E. Fernández, and A. Contreras. 2004. Influence of intramammary infection and non-infection factors on somatic cell counts in dairy goats. J. Dairy Res. 71:169-174.

McDougall, S., and M. Voermans. 2002. Influence of estrus on somatic cell count in dairy goats. J. Dairy Sci. 85:378-383

Moroni, P., G. Pisoni, G. Savoini, E. van Lier, S. Acuña, J. P. Damián, and A. Meikle. 2007. Influence of estrus of dairy goat on somatic cell count, milk traits, and sex steroid receptors in the mammary gland. J. Dairy Sci. 90:790-797.

Paape, M.J., B. Poutrel, A. Contreras, J. C. Marco, and A. V. Capuco. 2001. Milk somatic cells and lactation in small ruminants. J. Dairy Sci. 84(E. Suppl.): E237-E244.

Paape, M. J., G. R. Wiggans, D. D. Bannerman, D. L. Thomas, A. H Sanders, A. Contreras, P. Moroni, and R. H. Miller. 2007. Monitoring goat and sheep milk somatic cell counts. Small Rumin. Res. $68: 114-125$

Peaker, M., and J. L. Linzell. 1974. The effects of oestrus and exogenous oestrogens on milk secretion in the goat. J. Endocrinol. 61:231-240.

Pirisi, A., A. Lauret, and J. P. Dubeuf. 2007. Basic and incentive payments for goat and sheep milk in relation to quality. Small Rumin Res. 68:167-178.

Raynal-Ljutovac, K., A. Pirisi, R. de Crémoux, and C. Gonzalo. 2007. Somatic cells of goat and sheep milk: Analytical, sanitary, productive and technological aspects. Small Rumin. Res. 68:126-144.

SAS Institute. 2008. User's Guide. SAS Version 9.1. SAS Institute Inc., Cary, NC.

Walden-Brown, S. W., S. W. Martin, and B. J. Restall. 1999. Role of male-female interaction in regulating reproduction in sheep and goats. J. Reprod. Fertil. Suppl. 54:243-257.

Wilson, D. J., K. N. Stewart, and P. M. Sears. 1995. Effects of stage of lactation, production, parity and season on somatic cell counts in infected and uninfected dairy goats. Small Rumin. Res. 16:165169. 